\title{
Chirurgisches Management retroperitonealer Weichteilsarkome - eine Übersicht
}

\section{Surgical Management of Retroperitoneal Soft-Tissue Sarcomas - An Overview}

Autoren

Institute
B. Garlipp ${ }^{1}$, H.-U. Schulz ${ }^{1}$, M. Zeile ${ }^{2}$, H. Lippert ${ }^{1}$, F. Meyer ${ }^{1}$

${ }^{1}$ Universitätsklinikum Magdeburg, Klinik für Allgemein-, Viszeral- und Gefäßchirurgie, Magdeburg, Deutschland

${ }^{2}$ Universitätsklinikum Magdeburg, Klinik für Radiologie und Nuklearmedizin, Magdeburg, Deutschland

\section{Erratum}

B. Garlipp, H.-U. Schulz, M. Zeile, H. Lippert, F. Meyer

Chirurgisches Management retroperitonealer Weichteilsarkome - eine Übersicht

DOI 10.1055/s-0030-1247414

Online-Publikation: 19. Juli 2010

In der eFirst-Version des Artikels befindet sich im englischen Titel ein Rechtschreibfehler.

Der Titel lautet richtig „Surgical Management of Retroperitoneal Soft-Tissue Sarcomas - An Overview“ und nicht „Surgical Management of Retroperitoneal Soft-Tissue Sarcomas - An Overwiew“.
Bibliografie

DOI http://dx.doi.org/

10.1055/s-0030-1262533

Online-Publikation

Zentralbl Chir

(c) Georg Thieme Verlag KG

Stuttgart · New York .

ISSN 0044-409X

Korrespondenzadresse

Dr. Benjamin Garlipp

Universitätsklinikum

Magdeburg A. ö.R.

Klinik für Allgemein-,

Viszeral- und Gefäßchirurgie

Leipziger Straße 44

39120 Magdeburg

Deutschland

Tel.: $0391 / 6715500$

Fax: $0391 / 6715570$

benjamin.garlipp@med.ovgu.de 